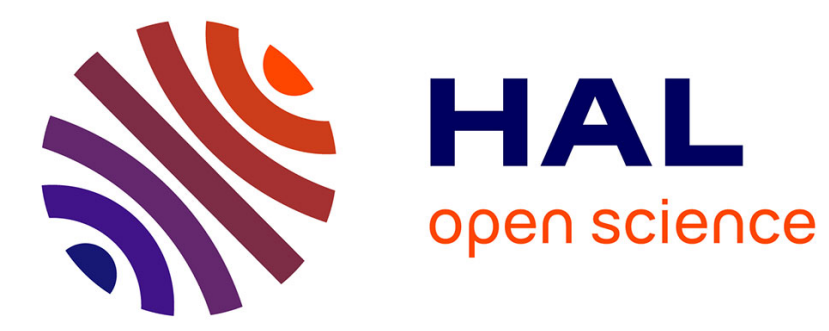

\title{
Sethi : Review Of 10 Years Of Development And Experimentation Of The Remote Sensing Platform
}

Rémi Baqué, Philippe Dreuillet, Hélène Oriot

\section{To cite this version:}

Rémi Baqué, Philippe Dreuillet, Hélène Oriot. Sethi: Review Of 10 Years Of Development And Experimentation Of The Remote Sensing Platform. RADAR 2019, Sep 2019, TOULON, France. hal-02502425

\section{HAL Id: hal-02502425 \\ https://hal.science/hal-02502425}

Submitted on 9 Mar 2020

HAL is a multi-disciplinary open access archive for the deposit and dissemination of scientific research documents, whether they are published or not. The documents may come from teaching and research institutions in France or abroad, or from public or private research centers.
L'archive ouverte pluridisciplinaire HAL, est destinée au dépôt et à la diffusion de documents scientifiques de niveau recherche, publiés ou non, émanant des établissements d'enseignement et de recherche français ou étrangers, des laboratoires publics ou privés. 


\section{Sethi : Review Of 10 Years Of Development And Experimentation Of The Remote Sensing Platform}

\author{
Rémi Baqué \\ DEMR \\ ONERA \\ F-13661 SALON AIR - France \\ remi.baque@onera.fr
}

\author{
Philippe Dreuillet \\ DEMR \\ ONERA \\ F-91123 PALAISEAU - France \\ philippe.dreuillet@onera.fr
}

\author{
Hélène Oriot \\ DEMR \\ ONERA \\ F-91123 PALAISEAU - France \\ helene.oriot@onera.fr
}

\begin{abstract}
ONERA is one of the leading organizations in experimental research on aeronautic topics. Works on Airborne Radar began forty years ago with the first airborne demonstrator named RAMSES. At the end of the aircraft's life (Transall C160), ONERA invested in the transfer of sensors to a Falcon 20 jet. This new platform, called SETHI, participated to its first operational test campaign on 2009. This paper summarizes the work carried out by SETHI and its contributions to airborne radar remote sensing research these last 10 years.
\end{abstract}

Keywords - Remote sensing; SAR; Very High Resolution; Moving target detection and tracking; Ground penetration; Optronic

\section{SETHI HISTORY}

In 1980s ONERA invested in a very powerful radar airborne platform onboard a Transall C160 (Fig. 1) called RAMSES [1]. It covered a large electromagnetic spectrum from $\mathrm{P}$ Band up to $\mathrm{W}$ Band with all sensors inside the cabin (Fig. 2 left). Side-looking antennas were flushed with the lateral door (Fig. 2 right)



Fig. 1. RAMSES onboard Transall C160


Fig. 2. View of RAMSES cabin (left) and side-looking antennas (right)

In 2008 the RAMSES Transall C160 reached the end of its life. With the objective of maintaining its airborne remote sensing capabilities, ONERA acquired its new airborne remote sensing system called SETHI. Developments were anticipated and began in 2005. The main difficulties were the reduction of cabin space and the pod design given the change in strategy for the antennas implementation due to the inability to open door in flight.

The three year studies led to the birth of SETHI, an underwing Pod concept with high power, low losses and high data rate cables in the wings (Fig. 3).

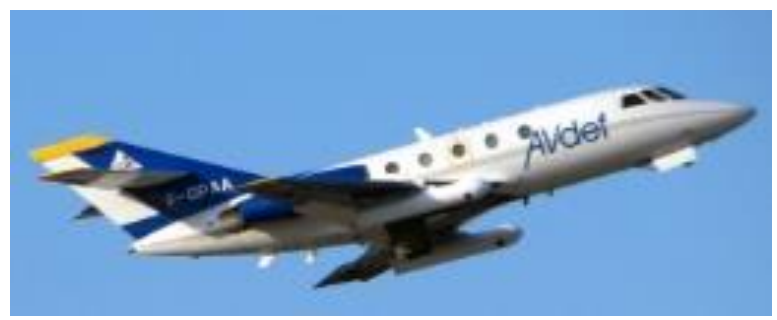

Fig. 3. SETHI platform

\section{PlATFORM DESCRIPTION}

SETHI has been developed to be a very flexible and multi-function research airborne platform.

\section{A. The Aircraft}

The SETHI remote sensing system is onboard a Falcon 20 (Fig. 3) that is an aircraft designed by Dassault Aviation fifty years ago. This aircraft, equipped with its payload, is EASA certified and thus can fly all over the world up-to 30000 feet, with 2.5 hours of autonomy and ground speed ranging from 200 to $400 \mathrm{kt}$ (typically $240 \mathrm{kt}$ during radar acquisition and $350 \mathrm{kt}$ during transit).

\section{B. Cabin layout and underwings Pods}

Control and command components are installed in a maximum five racks inside the cabin requiring three operators. Each rack is $22 \mathrm{U}$ high and able to carry $120 \mathrm{~kg}$ of payload. Last years, efforts have been made to reduce the size of radar components and thus the number of racks. It was then possible to add operator seats for optronic operation or onboard data processing. Classical cabin layout is now four racks with four operator seats (Fig. 4 right).

Radar antennas and electronic front end components are plugged in two Pods underwings which are able to carry heavy and large payloads working up to Ku band. The Podbased concept allows the easy integration and testing of new systems under the single certification of the Pods by authorities.

The Pod design (Fig. 4) includes a radome specifically designed for embedded aeronautical applications, with a useful length of $2.3 \mathrm{~m}$, a diameter of $0.535 \mathrm{~m}$ and a reachable payload of $120 \mathrm{~kg}$. Optical windows on the Pod nose are designed to accommodate optronic sensors in nadir or lateral looking configuration. 

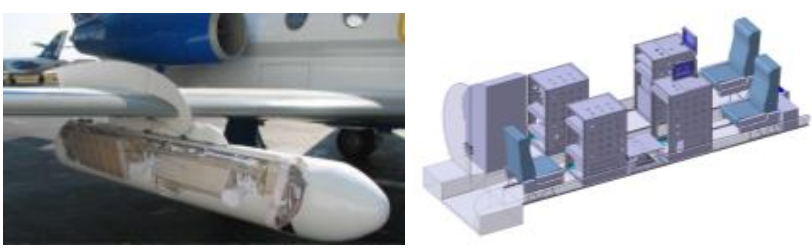

Fig. 4. SETHI Pod with representation of inside payload (left) and cabin layout (right)

One of the main difficulties with radar sensors is the electric consumption. SETHI has been equipped with very powerful electric generators able to deliver:

- $12 \mathrm{kVA}$ on three-phases $115 \mathrm{~V} / 400 \mathrm{~Hz}$

- $2.5 \mathrm{kVA}$ on $230 \mathrm{~V} / 50 \mathrm{~Hz}$

- $2 \mathrm{~kW}$ on $28 \mathrm{~V}$ DC

SETHI is therefore an ideal platform for testing large payloads with high power consumption and thus high performances.

\section{SENSOR DEVELOPMENTS}

\section{A. 2007 - The very first SETHI sensors}

At the RAMSES end of life, ONERA scientists had to choose the first radar components to adapt and transpose to SETHI. With the permanent objective of meeting civilian and defense needs, selection was made by favoring a wide spectral coverage but also high resolution and full polarization capabilities.

First SETHI Pod configuration was composed by full polarized $\mathrm{P}$ band radar in the left Pod associated with full polarized $\mathrm{L}$ and $\mathrm{X}$ band radars in the right Pod (Radar performances in TABLE I. ). All radar antennas were motorized on elevation axis to be able to change incidence angle between acquisitions (Fig. 5) and thus study radar interest in different geometries [2].

(a)
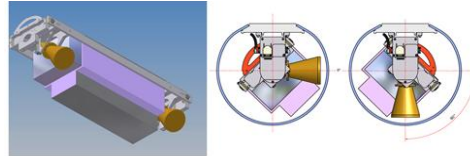

(b)
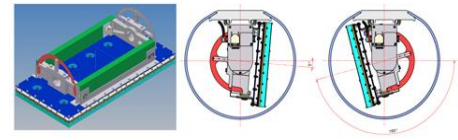

(c)
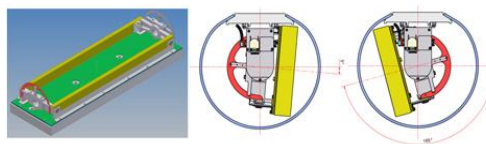

Fig. 5. SETHI first motorized antennas : $X$ Band (a), L Band (b) and P Band (c) antennas

First digital core system was based on $22 \mathrm{U}$ high VME chassis, $1 \mathrm{kVA}$ power consumption with performances in TABLE I.
TABLE I. SETHI FIRST RADAR PERFORMANCES (2007)

\begin{tabular}{|c|c|c|c|}
\hline Radar & $\mathbf{P}$ & $\mathbf{L}$ & $\mathbf{X}$ \\
\hline Carrier Frequency (MHz) & 435 & 1300 & 9500 \\
\hline $\begin{array}{l}\text { Bandwidth } \\
\text { (MHz) }\end{array}$ & $\begin{array}{c}50 \\
(11 \%)\end{array}$ & $\begin{array}{l}200 \\
(15 \%)\end{array}$ & $\begin{array}{l}1500 \\
(16 \%)\end{array}$ \\
\hline $\begin{array}{c}\text { Best resolution } \\
(\mathrm{cm})\end{array}$ & 300 & 75 & 10 \\
\hline Polarization & Full & Full & Dual \\
\hline Transmit Peak Power $(\mathbf{W})$ & 500 & 360 & 200 \\
\hline Antenna & $\begin{array}{l}\text { Patch } \\
\text { array }\end{array}$ & $\begin{array}{l}\text { Patch } \\
\text { array }\end{array}$ & Horns \\
\hline Elevation aperture & $80^{\circ}$ & $30^{\circ}$ & $14^{\circ}$ \\
\hline Azimuth aperture & $45^{\circ}$ & $10^{\circ}$ & $14^{\circ}$ \\
\hline Sampling channels & \multicolumn{3}{|c|}{8} \\
\hline Sampling freq. (GS/s) & \multicolumn{3}{|c|}{0.1} \\
\hline $\begin{array}{c}\text { Storage data rate }(\mathrm{GB} / \mathrm{s}) \\
\text { and capacity }(\mathrm{GB})\end{array}$ & \multicolumn{3}{|c|}{$\begin{array}{c}360 \mathrm{MB} / \mathrm{s} \text { total } \\
1000\end{array}$} \\
\hline
\end{tabular}

These sensors have been integrated onboard SETHI and tested in 2007 during the EASA certification flights. Fig. 6 presents one of the very first SAR images obtained with the SETHI platform.

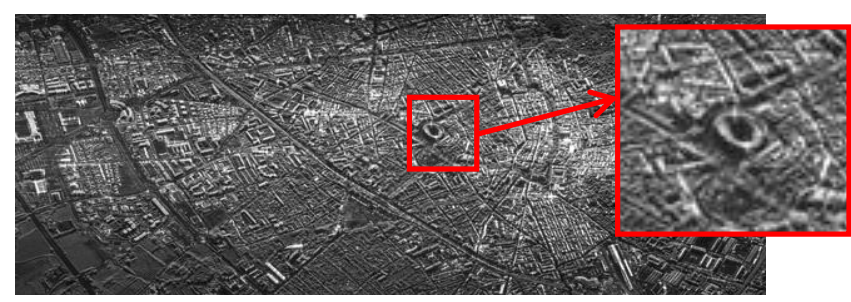

Fig. 6. X Band Hh $40 \mathrm{~cm}$ resolution SAR image of Nîmes (and zoom on the Roman historical arena)

Together with the EASA payloads certification for the SETHI platform, the 2007 flight test campaign confirmed its operability, allowing it to be deployed worldwide to meet the needs of scientists for data acquisition and proof of concept.

\section{B. 2009 - Radar and optronics improvement and first operational experiments}

In 2009, ONERA motivation was to explore lower frequencies and increase the low frequency sensor bandwidth. $\mathrm{P}$ band sensor is replaced by a full polarized 240 $\mathrm{MHz}$ bandwidth VHF/UHF sensor (Fig. 7). Main difficulty with longer wavelengths is the in-Pod antenna implementation, complicated by the addition of full polarization capability. Studies and design led to a large bandwidth dipole antenna (Fig. 7).

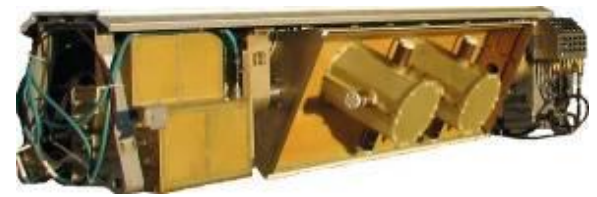

Fig. 7. In-Pod implementation of $\mathrm{VHF} / \mathrm{UHF}$ antenna

With the objective of improving the existing radars, the $\mathrm{X}$-Band SAR sensor is improved with a new capacity: full polarization mode.

At the same time ONERA invests in the second generation digital core, based on a compact VXS chassis (Fig. 8 right). First objectives were size and consumption reduction, and reliability improvement. Performances were also improved with 4 channels, 2 GS/s sampling frequency 
with 10 bits dynamic, $360 \mathrm{MB} / \mathrm{s}$ record data rate and $1.6 \mathrm{~TB}$ storage capacity.


Fig. 8. Comparaison of first (left) and second (right) generation digital core sizes

Finally, to increase its spectral coverage, SETHI has been equipped with hyperspectral optronic sensors from 0.4 to 1 $\mu \mathrm{m}$ wavelength and up to 160 spectral bands.

With these new components SETHI has been involved in various scientific campaigns all over the world, dedicated to: Foliage Penetration using bistatic configuration with LORA Sweden airborne SAR system [3]; defense and security using for instance Change Detection techniques [4]; maritime surveillance [5][6] and sea clutter measurement; ground penetration (Fig. 9) and biomass measurement [7][8] (Fig. 10) including tomographic capacities [9].



Fig. 9. Full polarized VHF/UHF (up) and optical (down) images of Saharan subsoil and Ksar Guilane oasis (Tunisia)
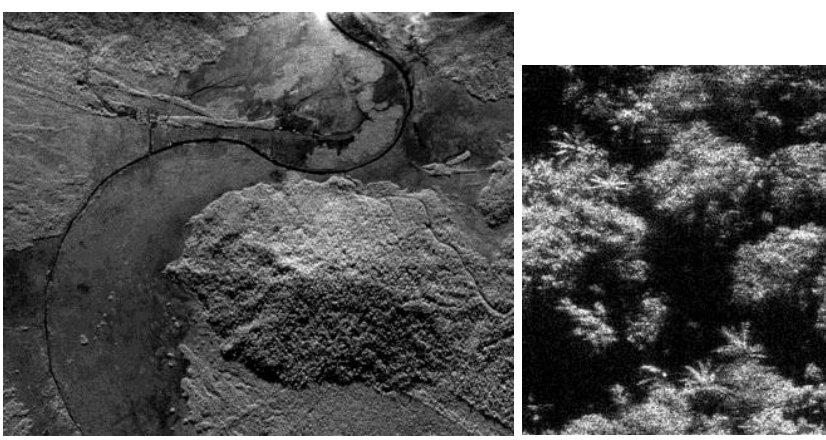

Fig. $10.10 \mathrm{~cm}$ resolution X-Band imagery of French Guyana Amazonian forest (left) and zoom on palm trees (right)

\section{2011 - UHR and multichannel radar, optronics and third generation digital core development and tests}

ONERA has been contracted by the French Ministry of Defense (MoD) to develop an X band long range and UltraHigh Resolution SAR sensor (Fig. 11 up). This new capability extends the SETHI spectrum coverage up to 12 $\mathrm{GHz}$, and is able to obtain $4 \mathrm{~cm}$ range resolution images. Its long range imagery capacity has been tested up to $60 \mathrm{~km}$ [10]. This French MoD program, called RAMSES-NG, also includes the third generation digital core development. It is based on the same VXS backplane standard than the previous system; with higher performances and advanced modes like real time programmable sampling window position and length, variable pulse repetition frequency, etc.

ONERA developed a variant of the UHR radar, dedicated to low speed ground target detection (GMTI mode), by keeping the transmit channel and replacing the receiving antenna by a patch array antenna combined into 4 receive channels (Fig. 11 down) and thus allowing Along Track Interferometry and Space-Time Adaptative Processing (STAP) algorithms.
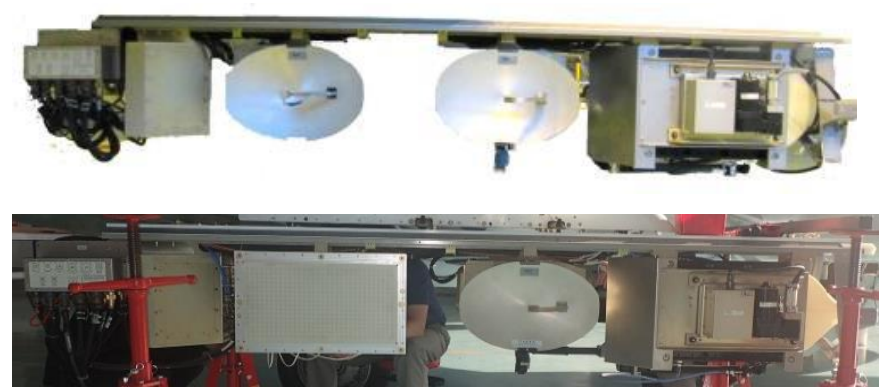

Fig. 11. In-Pod implementation of UHR long range $\mathrm{X}$ band SAR sensor (up) and 4 channel GMTI version (down)

\section{2016 - SETHI-2020 upgrade program and latest experiments}

After seven years of life, some sensor components being ageing or underperforming, ONERA decided to invest a significant financial effort for equipment upgrade and 3 years of study and development to modernize and improve the SETHI capacities and sensor performances.

This program, called SETHI-2020, enabled the acquisition of the latest generation of digital core, based on a PXI Express 4U chassis (Fig. 12). In addition to being more compact and powerful, this new digital system is primarily more reliable and scalable.

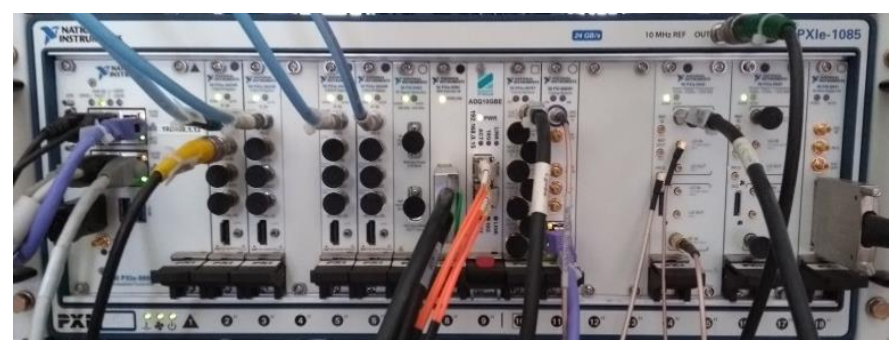

Fig. 12. SETHI PXI-Express digital core

The new performances (see TABLE II. ) have made possible to simplify the microwave synoptic of low frequency radars ( $\mathrm{L}$ and $\mathrm{V} / \mathrm{UHF}$ ) that have been modernized as well. L band and $\mathrm{X}$ band High Power Amplifiers have been replaced by $\mathrm{GaN}$ solid state amplifiers improving both performances and compactness.

The SETHI-2020 program also included the purchase of a new navigation system based on a very high-performance Optic Fiber Gyroscope inertial measurement unit (Fig. 13 left) and a new generation GNSS receiver, as well as a new guidance software for pilots and operators. These new architecture and performances made it possible to program 
and realize new trajectories with very high precision, as "solenoid-like" trajectories used to obtain circular imagery of ground moving target (Fig. 13 right).
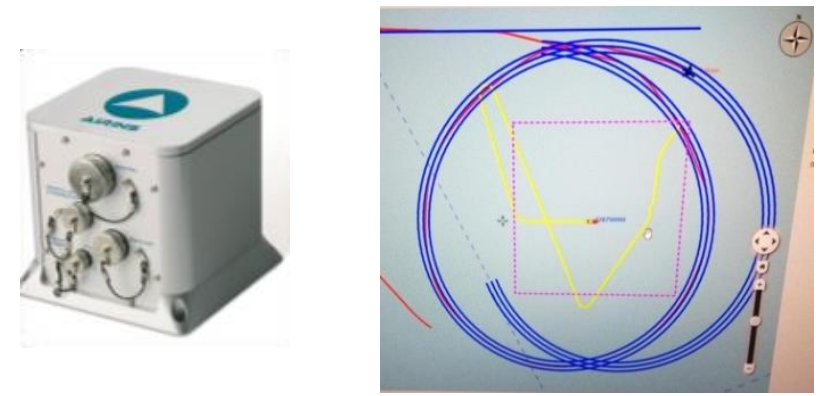

Fig. 13. SETHI new FOG INS (left) and real time onboard visualisation (right) of boat trajectory (yelow), aircraft trajectory (red) and theoretical trajectory corridor (blue) for moving boat circular imagery

Inertial data are also sent to the 2-axis motorized antennas in order to compensate in real time the aircraft attitude defects and allow antennas to remain pointed at the area of interest throughout the complete measurement.

SETHI has also been improved with the development of an onboard signal and SAR processing unit used after each acquisition for signal checking and validation, and image generation. SAR images are obtained between 5 to 15 minutes after the end of acquisition (depending on waveform, and image size). Change detection application is also available onboard, few minutes after second run acquisition.

SETHI new performances and capacities have been used in many scientific experiments in 2017 and 2018 for civilian and defense applications, as for example target VHR signature with circular measurement (Fig. 14), small objects and human detection with UHR circular imagery (Fig. 15) and ground and sub-surface characterization by low and high frequencies (Fig. 16).
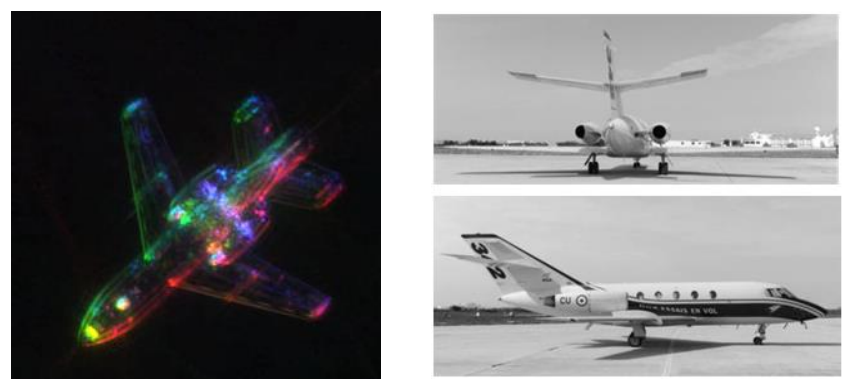

Fig. 14. X band Very High Resolution circular imagery of Falcon 20 aircraft (one color per azimuth direction)



Fig. 15. X band Ultra High Resolution circular imagery of hand tools, metalic boxes, chair, lying man with a mass and walking mn (one color per azimuth direction)

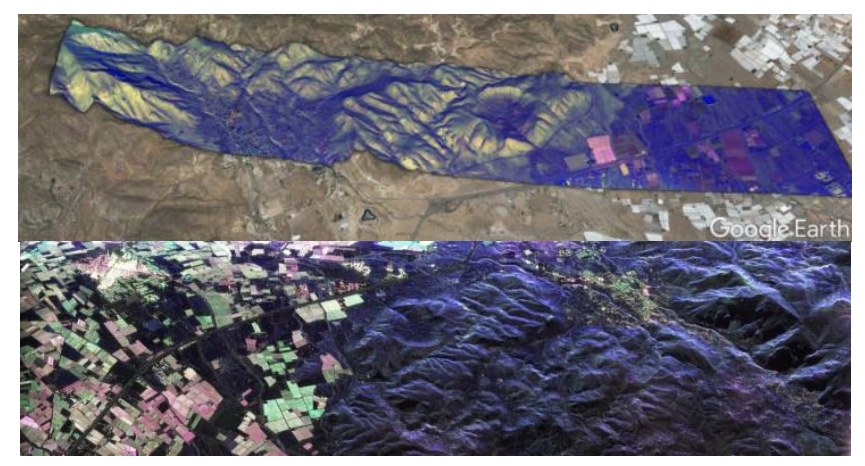

Fig. 16. Projected Pauli color composition of full polarized X-Band imagery (up) and full polarized L-Band imagery of Andalusia contryside (Spain) for ground and sub-sruface characterization

\section{SUMMARY AND PERSPECTIVES}

Since its operational launch 10 years ago, SETHI has proven its interest in the remote sensing scientific community through its multispectral (from microwaves to optical domain), multi-geometric and flexible capabilities. Its certification by EASA allows it to be implemented worldwide. The SETHI system is fully controlled and implemented by its ONERA operational and processing teams, also managing the logistic and ground truth measurements during missions all over the world (Fig. 17). 


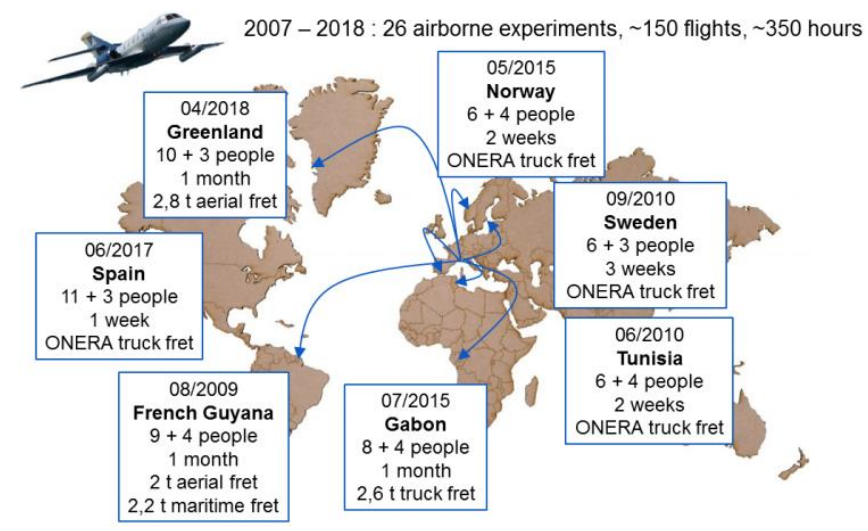

Fig. 17. SETHI's campaigns around the world

The performances achieved (TABLE II. and 0) thanks to the various internal ONERA or French MoD investments and development programs make it possible to satisfy the needs of scientists. But SETHI is in constant evolution to answer tomorrow's needs and for this reason other developments are underway:

- A full polarized $2 \mathrm{GHz}$ bandwidth $\mathrm{Ku}$ Band SAR sensor is under development and will be tested in flight in 2019.

- On-board signal and SAR processing will be upgraded to be a real-time SAR processing unit.

- Work is still in progress to miniaturize existing sensors and thus facilitate their integration.

TABLE II. SETHI RADAR PERFORMANCES (2018)

\begin{tabular}{|c|c|c|c|c|c|}
\hline Radar & V/UHF & $\mathbf{L}$ & $\mathbf{X}$ & X-UHR & Ku \\
\hline Center Freq. (MHz) & 340 & 1300 & 9500 & 10000 & 16500 \\
\hline $\begin{array}{l}\text { Bandwidth } \\
\text { (MHz) }\end{array}$ & $\begin{array}{c}240 \\
(70 \%)\end{array}$ & $\begin{array}{c}200 \\
(15 \%)\end{array}$ & $\begin{array}{l}1500 \\
(16 \%)\end{array}$ & $\begin{array}{l}4000 \\
(42 \%)\end{array}$ & 2000 \\
\hline $\begin{array}{l}\text { Best resolution } \\
(\mathbf{c m})\end{array}$ & 62 & 75 & 10 & 4 & 8 \\
\hline Polarization & Full (HV) & $\begin{array}{l}\text { Full } \\
\text { (HV) }\end{array}$ & $\begin{array}{l}\text { Full } \\
(\mathrm{HV})\end{array}$ & Dual (HV) & $\begin{array}{l}\text { Full } \\
\text { (HV) }\end{array}$ \\
\hline Tx Peak Power $(W)$ & 500 & 50 & 250 & 8000 & 250 \\
\hline Antenna & Dipoles & $\begin{array}{l}\text { Patch } \\
\text { array }\end{array}$ & Horns & Parabolic & Horns \\
\hline Elevation aperture & $100^{\circ}$ & $30^{\circ}$ & $16^{\circ}$ & $7^{\circ}$ & $16^{\circ}$ \\
\hline Azimuth aperture & $50^{\circ}$ & $10^{\circ}$ & $16^{\circ}$ & $5^{\circ}$ & $16^{\circ}$ \\
\hline Signal generation & \multirow{2}{*}{\multicolumn{5}{|c|}{2 channels, $2.5 \mathrm{GS} / \mathrm{s}, 1 \mathrm{GHz}$ bandwidth, 16 bits }} \\
\hline Sampling & \multirow{2}{*}{\multicolumn{5}{|c|}{$\begin{array}{c}4 \text { channels, } 1 \mathrm{GS} / \mathrm{s} \mathrm{I} / \mathrm{Q}, 12 \text { bits } \\
3.4 \mathrm{~GB} / \mathrm{s}, 7 \mathrm{~TB} \text { capacity }\end{array}$}} \\
\hline Storage & & & & & \\
\hline
\end{tabular}

TABLE III. SETHI OPTRONIC PERFORMANCES (2018)

\begin{tabular}{|c|c|c|c|c|}
\hline Optronic & Optical & VNIR & SWIR & LWIR \\
\hline Wavelength $(\mu \mathrm{m})$ & $0.4-0.9$ & $0.4-1$ & $1-2.5$ & $7.7-9.3$ \\
\hline Nb. pixels & $\begin{array}{c}39 \mathrm{M} \\
7300 \times 5400\end{array}$ & 1600 & 320 & $640 \times 512$ \\
\hline Nb. spectral Bands & & 160 & 256 & \\
\hline Nb. bits & 16 & 12 & 14 & \\
\hline $\begin{array}{l}\text { Resolution (m) } \\
\text { (@ range) }\end{array}$ & $\begin{array}{c}0.17 \\
\text { (@ } 2.7 \mathrm{~km} \text { ) }\end{array}$ & $\begin{array}{c}1 \times 2 \\
\text { (@ } 2.7 \mathrm{~km} \text { ) }\end{array}$ & (@ $2.7 \mathrm{~km}$ ) & $\begin{array}{l}0.3 \text { or } 0.6 \\
\text { (@ } 2 \mathrm{~km} \text { ) }\end{array}$ \\
\hline Geometry & $\begin{array}{l}\text { Nadir or Radar } \\
\text { LOS }\end{array}$ & Nadir & Nadir & Nadir \\
\hline $\begin{array}{c}\text { Swath (m) } \\
\text { (Field of view) }\end{array}$ & $\begin{array}{l}1300 \times 950 \\
\left(27^{\circ} \times 20^{\circ}\right)\end{array}$ & $\begin{array}{c}1600(@ 2.7 \\
\mathrm{km}) \\
\left(34^{\circ}\right)\end{array}$ & $\begin{array}{c}700 \text { (@ } 2.7 \\
\mathrm{~km}) \\
\left(14^{\circ}\right)\end{array}$ & $\begin{array}{c}192 \times 154 \mathrm{~m} \\
\text { or } \\
385 \times 308 \mathrm{~m} \\
\text { (@ } 2 \mathrm{~km})\end{array}$ \\
\hline
\end{tabular}

\section{ACKNOWLEDGMENT}

Authors wish to acknowledge DGA (French MoD) for its financial support to campaigns and RAMSES-NG radar developments.

Authors would like to thank all the SETHI team members: N. Castet, P. Fromage, J. Henrion, JF. Nouvel, O. Ruault du Plessis, S. Angelliaume, O. Boisot, F. Brigui, H. Cantalloube, M. Chanteclerc, O. Couderc, X. du Hamel de Milly, X. Dupuis, P. Martineau, J. Martinot-Lagarde, G. Point, V. Wasik, F. Schreber

\section{REFERENCES}

[1] Dreuillet, "The ONERA RAMSES SAR: Latest significant results and future developments", Proc. Radar 2006, Verona NY (USA)

[2] Bonin, Dreuillet, "The Airborne SAR System SETHI : Airborne Microwave Remote Sensing Imaging System" Proc. EUSAR 2008, Friedrichshafen (Germany)

[3] Baqué, Ulander et al., "Results of the LORAMbis Bistatic VHF/UHF SAR Experiment for FOPEN", Proc. Radar 2011, Chengdu (China)

[4] Oriot et al. "Coherent change detection in urban environment", Proc. Proc. EuSAR 2010, Aachen (Germany)

[5] Angelliaume et al., "Hyperspectral and Radar Airborne Imagery over Controlled Release of Oil at Sea" Sensors 2017, 17, 1772

[6] Angelliaume et al., "Multifrequency Radar Imagery and Characterization of Hazardous and Noxious Substances at Sea," in IEEE Transactions on Geoscience and Remote Sensing, vol. 55, no. 5, pp. 3051-3066, May 2017

[7] Dubois-Fernandez et al., "The TropiSAR Airborne Campaign in French Guiana: Objectives, Description, and Observed Temporal Behavior of the Backscatter Signal" in IEEE Transactions on Geoscience and Remote Sensing, vol. 50, no. 8, pp. 3228-3241, Aug. 2012

8] Dubois-Fernandez et al. "Preliminary results of the AfriSAR campaign", Proc. EuSAR 2016, Hamburg (Germany)

[9] Wasik et al. "The AfriSAR Campaign: Tomographic Analysis With Phase-Screen Correction forP-Band Acquisitions," in IEEE Journal of Selected Topics in Applied Earth Observations and Remote Sensing, vol. 11 , no. 10, pp. 3492-3504, Oct. 2018

[10] Baqué et al., "Ultra-High Resolution and Long Range X-Band Airborne SAR System", Radar 2018, Brisbane (Australia) 